\title{
Simulations of Swirling Fires Controlled by Channeled Self-generated Entrainment Flows
}

\author{
K. SATOH \\ National Research Institute of Fire and Disaster \\ Mitaka, Tokyo 181, Japan \\ K.T. YANG \\ Department of Aerospace and Mechanical Engineering \\ University of Notre Dame \\ Notre Dame, IN 46556, USA
}

\begin{abstract}
In an earlier study experimental observations of swirling fires based on self-generated swirling flows were undertaken. The swirl was caused by properly channeling the entrainment flow due to the fire itself. It was found that one of the most significant parameters governing the combustion process and the stability of the whirling flame was the entrainment flow controlled by the presence of symmetrical gaps separating the square vertical bounding walls surrounding the fire. In the present study, the physical phenomena of how the channeled entrainment flow affects the whirling flame has been simulated numerically by an approximate fire field model, which captures essentially the same whirling fire phenomena as observed in the experiments. In particular, the quantitative effect of gap sizes between bounding walls and several other parameters such as heat load, fuel size, and enclosure wall height on the plume dynamics and whirling flame stability have been numerically determined.
\end{abstract}

KEYWORDS: Swirling Fires, Fire Simulation, Field Modeling, Flame Stability, Entrainment Flows

\section{INTRODUCTION}

Urban and forest fires are characterized by large-scale whirling flames in the form of tight swirling fire plumes. Despite their frequent occurrences, still relatively little is known about their physics and dynamics. One difficulty to study such fire whirls is that they must first be created in the laboratory or in the open field. Some success has been reported in the literature in this regard. For instance, swirling fires can be generated by surrounding the fire with a rotating mesh cylinder [1], or by small multiple fires placed in a wind tunnel [2], or in free air with a prevailing wind [3]. Another recent scheme of creating swirling fires is by means of 
channeling the entrainment flows induced by the fire itself in a tangential direction around the fire, thus imparting rotational motion to the fire causing it to swirl. The channeling can be provided by a walled vertical cylinder surrounding the fire with vertical wall slits and guide vanes [4]. The difficulty in the creation of fire whirls in the laboratory has further impeded the study of their physics and dynamics, especially in the determination of conditions which cause fire whirls and sustain their integrity. Such conditions are important to enable us to mitigate the high destructive power of fire whirls relative to urban and forest fires.

The generation of stable fire whirls in the laboratory and the study of certain physical aspects of such fire whirls are the objective of a recent experimental study [5], in which a burning flame was surrounded by a vertical square enclosure open at the top, together with physical symmetrical gaps provided at each of the four corners of the enclosure between adjacent vertical enclosure walls, similar to the more recent studies of Satoh [4] and Saito and Cremers [6]. The resulting swirling fire was systematically observed in terms of the ability of the channeled induced flows to maintain its integrity. The geometry in the study was deemed pertinent to urban fires engulfing a city block. One important conclusion of the experimental observations is that the gap plays a pivotal role in creating the fire whirl as well as in affecting its stability. In addition, it was further observed that both of these two characteristics were hydrodynamic in nature, i.e. the generation of the fire whirl and its stability to maintain its integrity were essentially due to entrainment flows through the gaps and only in an indirect way, to other effects such as combustion and radiation. It is in this regard that it is important to determine, for a given fire, the effect of changing the gap size on the detailed hydrodynamics of the flow field, as they in turn affect the whirling flame characteristics.

The purpose of the present paper is to present the results of a numerical study based on a three-dimensional field model originally developed for room fires on the effects of several parameters on the dynamics and the integrity of whirling fires, thus gaining more detailed physical insight to the whirling- fire phenomena. In the following sections, the dynamics of the whirling fire, as observed in the experiments, will first be described and be utilized later to compare with the numerically simulated results. The numerical model, its justifications, and the computation will then be presented next. This is then followed by the results of the simulations and their discussion and conclusions.

\section{EXPERIMENTAL OBSERVATIONS}

Details of experimental observations dealing with different fuels, square-enclosure geometry, fuel pan size and location, and gap sizes have already been described by Satoh and Yang [5], and hence will not be repeated here. The enclosure geometry is shown in Figure 1 (a). It suffices here to describe a general scenario for a typical whirling fire located inside a square enclosure with vertical corner gaps. When the fuel in a centrally located pan is first ignited, the flame height is always relatively short initially, and then increases with time. Very quickly, however, the flame starts to rotate about the enclosure vertical axis as the entrainment air flowing through the gaps reaches the fire, with the flame leaning toward the inside walls of the enclosure. Shortly thereafter, the flame stabilizes itself, begins to stand straight up, and also elongates and whirls along its own vertical axis. The stability of the whirling flame persists as long as the flame remains inside the walled enclosure and burning continues. A typical whirling flame is shown in Figure 1 (b) for a kerosene fire with a fuel-pan diameter of $12 \mathrm{~cm}$, wall height of $1.8 \mathrm{~m}$, square-enclosure width of $70 \mathrm{~cm}$, and a gap size of $7 \mathrm{~cm}$, and the flame height was observed at $1.7 \mathrm{~m}$. Of great interest also is the fact that there exists a critical gap size beyond which the fire does not whirl.

\section{NUMERICAL FIELD MODELING OF WHIRLING FLAMES}

Largely because of the ever-increasing computing power now available generally, numerical 


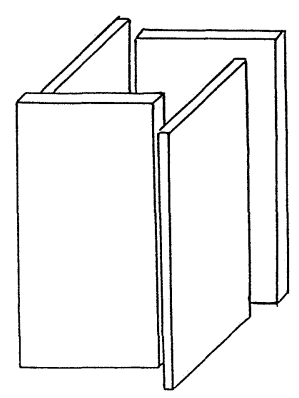

(a)

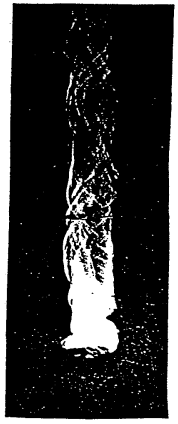

(b)

FIGURE 1 (a) Schematic of Encolsure Geometry and (b) A Typical Whirling Fire

simulation of fire and fire spread based on field models has received increasing attention. In any of such models, phenomenological submodels such as for complex three-dimensional geometry, full compressibility, strong buoyancy, turbulence, thermal radiation, and combustion are needed to close the system of governing equations so that the instantaneous field variables such as velocities, temperature, species, and pressure can all be calculated in a given fire scenario. However, as discussed recently in some detail by Yang [7], none of these modeling efforts is trivial, even though many of the effects individually can be modeled at the present time. The most difficult is the modeling of turbulent combustion. As a result, contrary to what some people, particularly the commercial CFD package vendors, may claim, there does not exist a general-purpose field model for all types of fires. On the other hand, despite their shortcomings and limitations, some of the available field models designed particularly for fire simulations can, along with some experimental data, play an essential role in delineating the important physics involved in specific fire scenarios, thus enabling us to gain the needed insight to the fire phenomenon under consideration [7].

In the present study the three-dimensional UNDSAFE field model, which accounts for full compressibility and strong buoyancy has been used to simulate the swirling fires in a square enclosure with symmetrical vertical corner gaps, as observed in the experiments described previously [5]. Despite its inherent limitation of not having an operational combustion submodel, this field model has been successfully used to simulate a variety of room fire scenarios [8-12] including the simulation of full-burn tests in a nuclear reactor containment building [12]. Even though this field model also has the capability of accommodating turbulence, transparent thermal radiation, and higher-order differencing for convective terms in the governing equations, further approximations of using constant viscosity and Prandtl number, and neglecting radiation effects have been made to simplifying the computations. Furthermore, the upwind differencing for the convective terms in the original UNDSAFE code has been retained. These approximations can be justified as follows: The upwind differencing scheme is not expected to introduce significant errors in the computations, since the bulk flow in the square enclosure is mainly upward and the entrainment flows are relatively small except in the lowest part of the enclosure [13]. Also, as already pointed out previously in the experimental observations of the whirling flames, the over-riding effects on the generation and stability of whirling flames are the entrainment flows through the gaps, and the thermal effects such as radiation and combustion only play a secondary role. 
Consequently, neglecting thermal radiation does not alter the qualitative effects of the entrainment flows. Similarly, the turbulence effects only smear out the large and small velocity gradients, and do not materially change the inherent velocity fields. The overall justification of these approximations is that in this study we are specifically not attempting to predict the exact behaviors of the whirling fire, but to see whether the field model used indeed captures at least qualitatively the same whirling-flame phenomena as that observed in the experiments.

The governing equations in any field model for fires are the first-principle time-dependent three-dimensional conservation equations for momentum, mass and energy. Since there are no combustion and radiation submodels, the species conservation equations are not needed. Boundary conditions for the flow field are the standard ones, except at the upper reaches of the vertical walls and along the gaps where the no-slip conditions are utilized. The flow field outside the enclosure is also calculated, and includes the effect of wall extensions at the gaps. Boundary conditions of the thermal field at the openings of the enclosure are given by vanishing normal temperature gradients for flow leaving the enclosure, and by the ambient temperature for flow entering the enclosure. Since no combustion submodel is used, heat source representing the fire must be prescribed. In real-life fires, combustion takes place not just above the fuel pan, but continues in the hot plume upward. The plume top, which defines the flame height, is the location where combustion essentially stops. A somewhat realistic heat-source model specifies an ad hoc nonuniform distribution of volumetric heat generation in a volume represented by a right cylinder over the fuel pan with cross sections identical to that of the fuel pan. In addition, the volumetric heat-source strengths are adjusted in the vertical direction to approximate that of real fire plumes such that they decrease from a maximum just above the fuel pan, 9 times that of a unit strength over a height of $5 \%$ of the flame height, to 3 times the unit strength covering the next $25 \%$ of the flame height, and a strength equal to the unit strength from there to the top of the flame. This distribution is only an approximation based on what could be reasonably expected in a liquid-fuel fire. The total heat-generation rate, which determines the unit strength, should correspond to the anticipated heat release rate, which is related to the fuel consumption rate, the heating value of the fuel, and an overall combustion efficiency.

Because of space limitations, the governing equations, the corresponding finite-volume equations, and the method of solution will not be given here, and the interested reader is referred to the papers of Satoh [8,10], Raycraft et al. [9], and Yang et al. [11] for details. In the present simulation study, unless otherwise specified, the total heat source is taken to be 20 $\mathrm{KW}$, which is of the same order as that in the experiments using heptane as a fuel. The square enclosure has a width of $63 \mathrm{~cm}$ to $75 \mathrm{~cm}$, a height of $0.3 \mathrm{~m}$ to $1.8 \mathrm{~m}$, and a flame height of either $90 \mathrm{~cm}$ or $150 \mathrm{~cm}$, and a square fuel area, $15 \mathrm{~cm}$ to $21 \mathrm{~cm}$ to a side. The gap sizes range from $6 \mathrm{~cm}$ to $45 \mathrm{~cm}$. The uniform grid spacing in all three directions is $3 \mathrm{~cm}$, and the domain of calculations is of the size up to $129 \mathrm{~cm} \times 129 \mathrm{~cm} \times 183 \mathrm{~cm}$, consisting of 112,789 calculation cells. All calculations have been made on a HP workstation.

\section{SIMULATION RESULTS}

To study the effects of gap size on the dynamics of the whirling flame, five cases have been calculated, each corresponding to a specific gap size. In each case, time-dependent velocity and temperature fields inside the enclosure have been determined. In addition, the total net entrainment flows at several heights have also been calculated. Other effects have also been simulated in five additional cases including those of total heat load, fuel area size, and enclosure height. The specific parameters for the ten simulation cases are given in Table 1. Also, as a matter of course, total horizontal sectional heat and mass balances are checked to see if the bulk heat and mass conservations are observed. Of particular interest are the dynamics of the fire before and after the establishment of whirling flames and how they compare with the experimental observations, whether a critical gap size exists at which 
whirling fire cannot be initiated, and the physical details of the flow through the gaps as a function of height, which determines the entrainment flows. The large amount of computational data prevents us to show all the results, and hence only representative and interesting ones will be selected and presented in the following.

TABLE 1 Numerically Simulated Cases

$\begin{array}{ccccc}\begin{array}{c}\text { Simulation } \\ \text { Case }\end{array} & \begin{array}{c}\text { Enclosure Dimension } \\ \text { Height } \times \text { Base }(\mathrm{cm})\end{array} & \begin{array}{c}\text { Heat Source Volume } \\ \text { Height } \times \text { Base }(\mathrm{cm})\end{array} & \begin{array}{c}\text { Gap Size } \\ (\mathrm{cm})\end{array} & \begin{array}{c}\text { Total Heat Load } \\ (\mathrm{KW})\end{array} \\ 1 & 180 \times 75 \times 75 & 150 \times 21 \times 21 & 6 & 20 \\ 2 & 180 \times 75 \times 75 & 150 \times 21 \times 21 & 9 & 20 \\ 3 & 180 \times 75 \times 75 & 150 \times 21 \times 21 & 12 & 20 \\ 4 & 180 \times 75 \times 75 & 150 \times 21 \times 21 & 18 & 20 \\ 5 & 180 \times 75 \times 75 & 150 \times 21 \times 21 & 24 & 20 \\ 6 & 180 \times 75 \times 75 & 150 \times 21 \times 21 & 12 & 10 \\ 7 & 180 \times 63 \times 63 & 90 \times 15 \times 15 & 12 & 20 \\ 8 & 180 \times 63 \times 63 & 90 \times 21 \times 21 & 12 & 20 \\ 9 & 60 \times 63 \times 63 & 90 \times 21 \times 21 & 12 & 20 \\ 10 & 90 \times 63 \times 63 & 90 \times 21 \times 21 & 12 & 20\end{array}$

Results of Case 8 in Table 1 will first be described to illustrate the general dynamics of a whirling flame in a time period after the fire ignition. The total heat load of $20 \mathrm{KW}$ is nonuniformly distributed in a volume of $90 \mathrm{~cm} \times 21 \mathrm{~cm} \times 21 \mathrm{~cm}$ above the $21 \mathrm{~cm} \times 21 \mathrm{~cm}$ fuel area, in accordance with the ad hoc rule given previously, which is what may be expected in a real fire. The results for this case are shown in Figure 2. At each time instant indicated, the left figure indicates the vertical isotherms through the center of the enclosure as viewed from two perpendicular planes. The upper right figures are the horizontal section isotherms at three different heights of $15 \mathrm{~cm}, 60 \mathrm{~cm}$, and $120 \mathrm{~cm}$, repectively, and the right lower figures are the corresponding velocity plots at the same sections. In Figure 2(a) at $21.6 \mathrm{sec}$ from ignition, which is representative of the fire behavior at early times, the fire plume is essentially centered in the enclosure, and is quite stable due to the presence of confining walls. The ambient temperature is set at $20 \mathrm{deg} \mathrm{C}$, and the outmost isotherm is for $50 \mathrm{deg} \mathrm{C}$, and for the successive isotherms going inward, the temperature increment is 50 deg.C. At the next time instant at $27.0 \mathrm{sec}$, the plume has moved, now leaning toward the right wall, a scenario caused by the entrainment flow as also observed in the experiments described previously [5]. It can also been seen that the plume temperature decreases in the vertical direction and that there is already a twisting movement in the plume evidently due to the entrainment flow. At the next instant at $32.4 \mathrm{sec}$, the plume is continuing its rotation and also growing in size. Of particular interest is that the plume at the $120 \mathrm{~cm}$ height is already moving toward the center, while at the other two vertical locations, the plume is still essentially in the regions close to the wall. At $37.8 \mathrm{sec}$, the plume is now back in the centered location, almost constant in its size in the vertical direction, and possesses a strong rotation. Also, the vertical velocity plot, which is not shown here because of space limitations, indicates that there is swirling motion very similar to that shown in Figure 1. All these indications suggest that now we have a whirling flame at this instant. Next at $43.2 \mathrm{sec}$, the whirling persists and it is also accompanied by an off-center movement of the entire plume inside the enclosure, now in the distinct form of a cone with a secondary rotation closed to the walls. It is seen that this scenario continues at $48.6 \mathrm{sec}$. The entire behavior of the initiation of the whirling flame and its subsequent stability is quite consistent with what was observed in the experiments [5], and lends some support to the validity of the approximate field model used in this study, at least qualitatively. 
(a) $21.6 \mathrm{sec}$
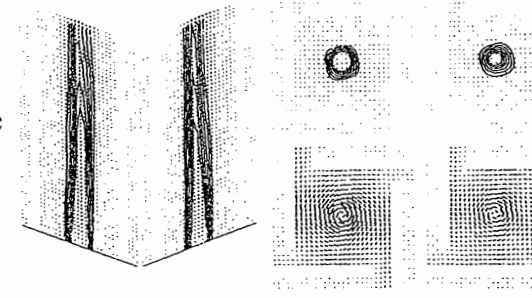

(69)

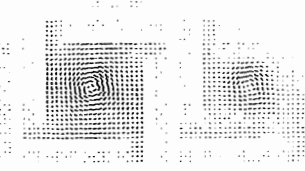

(b) $27.0 \mathrm{sec}$
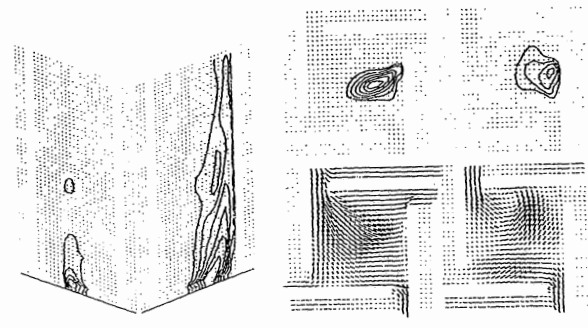

(1)

(c) $32.4 \mathrm{sec}$
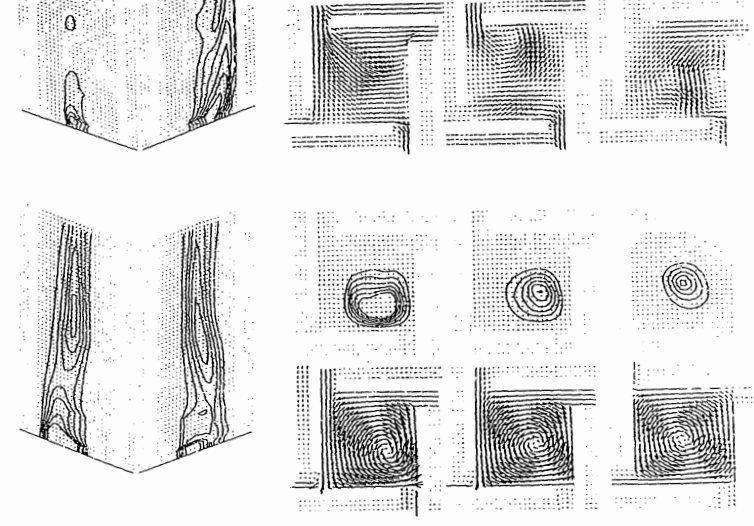

(d) $37.8 \mathrm{sec}$
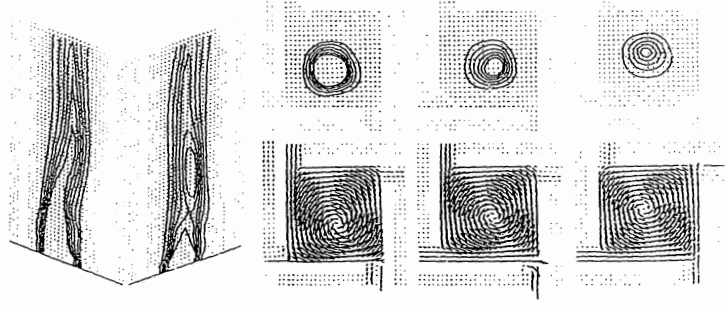

FIGURE 2 Simulated Temperature and Velocity Fields for Case 8. 
(e) $43.2 \mathrm{sec}$
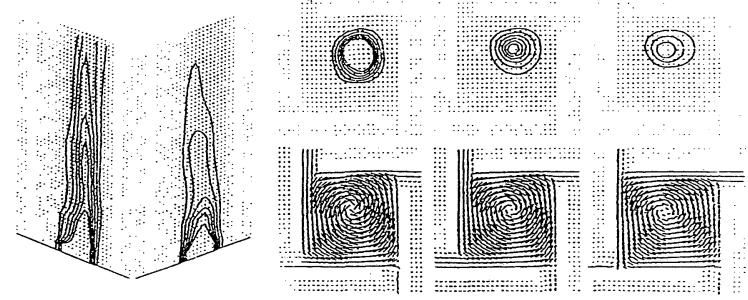

$48.6 \mathrm{sec}$
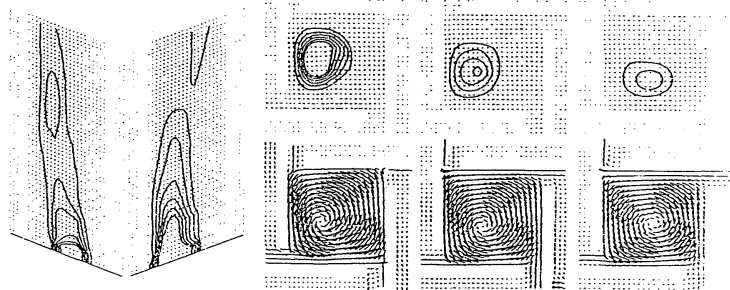

(g) $54.0 \mathrm{sec}$
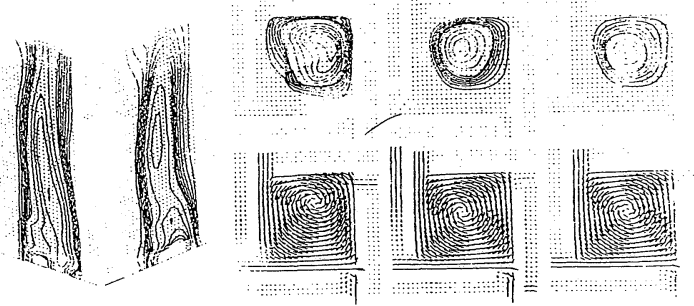

FIGURE 2 Simulated Temperature and Velocity Fields for Case 8 (Continued).

In the recent experimental study [5], it was suggested that the most important effect on the dynamics of whirling fires was that of the entrainment flow through the vertical gaps. In the present numerical simulations, this entrainment flow has been calculated to determine whether they are indeed closely related to the dynamics of the whirling fires. For the simulation Case 8 in Table 1, the computed instantaneous total flow rates are shown as a function of the height above the fuel pan in Figure 3. It is of interest to note that the total mass flow rate at a given time instant increases with height, and reaches close to a maximum at the top of the wall, indicating that the most entrainment flows occur at the lower levels and almost no entrainment flow near the top. The obvious reason is that the mass flow rate is strongly affected by the buoyancy forces, which are greatest in the lower levels due to high local volumetric heat load there. Even more interesting is the fact that there is a dramatic increase in the entrainment flow at any height from $21.6 \mathrm{sec}$ to $32.4 \mathrm{sec}$, which coincides with the initiation of the whirling 


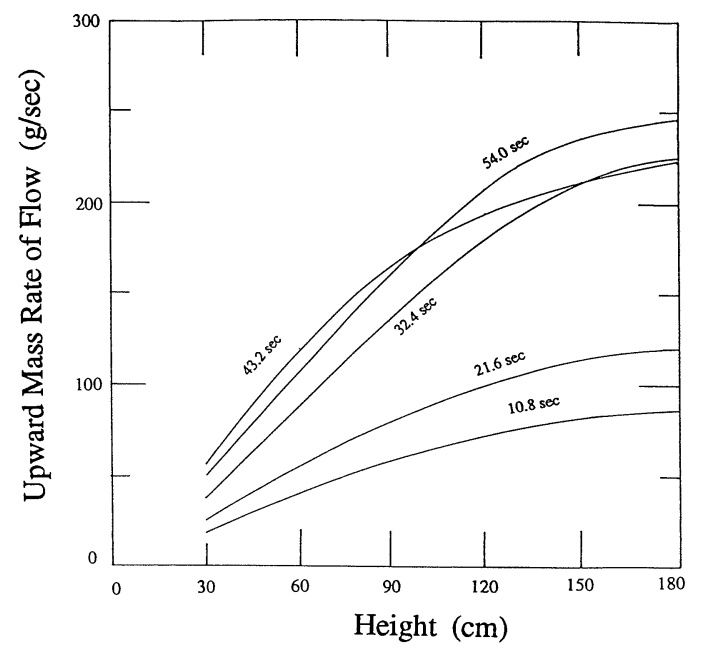

FIGURE 3 Upward Mass Rate of Flow for Simulation Case 8

flame scenario shown in Figure 2. Consequently, the large mass flow rates, especially those occuring at the higher levels, can be used as a quantitative indication of the initiation of whirling flames, thus tending to confirm what was observed in the experiments. Furthermore, Figure 3 also suggests that such a mass-flow rate plot can be interpreted as consisting of three time regimes: the early pre-whirling regime of stable non-rotataing plumes, the post-whirling regime where whirling persists, and an in-between transition regime in which the bulk plume rotates slowing, while leaning toward the walls. However, the postwhirling regime, which is characterized by a flame whirling about its axis, could possibly become unstable due to other effects, such as, for instance, a short wall height situation [5].

In a more recent experiment, the data of which was not included in those discussed by Satoh and Yang [5], heptane was used as a fuel and placed in a circular fuel pan, $12 \mathrm{~cm}$ in diameter, which in turn was placed in a square enclosure with dimensions of $180 \mathrm{~cm} \times 75 \mathrm{~cm} \times 75 \mathrm{~cm}$. Fire tests were conducted in which entrainment flow velocities normal to the gap was measured with hotwire anemometers at different heights for gap sizes of $2.5 \mathrm{~cm}, 5 \mathrm{~cm}, 8 \mathrm{~cm}$, and $10 \mathrm{~cm}$. Stable whirls were observed for all gap sizes. The velocity measurements in the post-whirling regimes are shown in Figure 4. It is seen that high entrainment flows occur at lower levels and become vanishingly small at locations near the top. This result is again completely compatible with the numerical simulations as shown in Figure 3. Here is another indication that the current approximate field model captures a significant part of the physics of whirling fires. Thus it would be of great interest to compare the numerically obtained total entrainment-flow value, which is the same as the mass flow rate at the top of the enclosure with the corresponding experimental data, which can be directly calculated by integrating a pertinent curve in Figure 4 over the total height. Such an exercise has been carried out by comparing the simulation CASE 1 with a $6 \mathrm{~cm}$ gap in the post-whirling regime with the experimental data for a $5 \mathrm{~cm}$ gap. Despite the differences in some of the parameters and uncertainties in the experiment, it is found that the total entrainment flow rate from the experiment is $195 \mathrm{~g} / \mathrm{sec}$ which is of the same order when compared to the calculated value of $259 \mathrm{~g} / \mathrm{sec}$. 


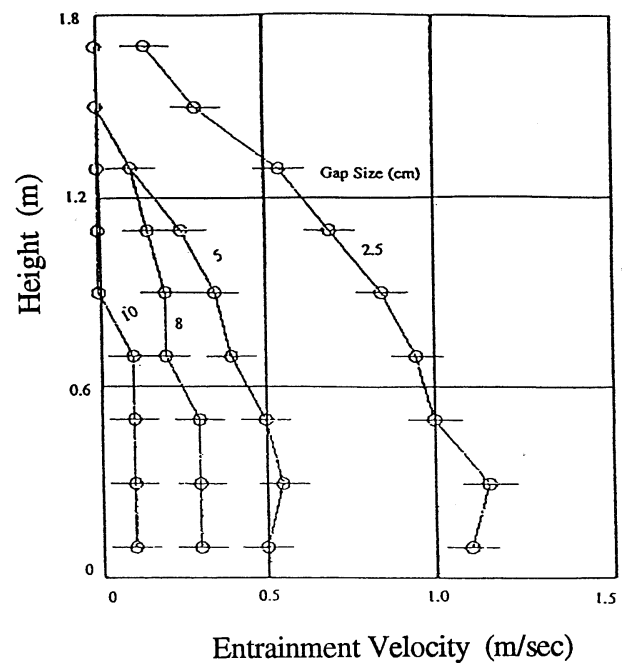

FIGURE 4 Entrainment Velocity for Experiment

In view of the above overall comparisons which suggest some degree of confidence of the approximate field model, it is now possible to extract some physical insight from the simulation cases given in Table 1 . Case 1 through 5 deal with the same parameters, but with varying gap sizes ranging from $6 \mathrm{~cm}$ to $24 \mathrm{~cm}$. By using the previously suggested criterion that initiation of whirls is associated with greatly increased mass rate of flow at the instant of whirl initiation, it is found that in the numerical results that with $6 \mathrm{~cm}$ and $9 \mathrm{~cm}$ gap sizes, the whirl occurs between $40.5 \mathrm{sec}$ and $45.0 \mathrm{sec}$, while for gap sizes of $12 \mathrm{~cm}$ and $18 \mathrm{~cm}$, it occurs between $45.0 \mathrm{sec}$ and $49.5 \mathrm{sec}$. For a gap size of $24 \mathrm{~cm}$, the whirl appears at $56.3 \mathrm{sec}$. There is evidence that as gap size increases, the initiation of flame whirl is delayed. Also, the mass rates of flow at the $1.8 \mathrm{~m}$ level, i.e. at the top of the enclosure, are $245 \mathrm{~g} / \mathrm{sec}, 268 \mathrm{~g} / \mathrm{sec}$, $168 \mathrm{~g} / \mathrm{sec}, 140 \mathrm{~g} / \mathrm{sec}$, and $139 \mathrm{~g} / \mathrm{sec}$, for the $6 \mathrm{~cm}, 9 \mathrm{~cm}, 12 \mathrm{~cm}, 18 \mathrm{~cm}$, and $24 \mathrm{~cm}$ gap size cases, respectively, all at the same time instant in the post-whirling regime. This is again, at least qualitatively, compatible with the experimental data shown in Figure 4, where it is clearly seen that increase in the gap size reduces the entrainment flow velocities. The numerical simulation also suggests that the maximum flame temperatures do not vary greatly with the gap size. For Cases 1 through 5, the maximum flame temperature varies only in a relatively narrow range from $512 \mathrm{deg} C$ to $635 \mathrm{deg}$.C. This is reasonable since the maximum flame temperature is closely related to the total heat load, and less so with the local flow conditions. Also in all these five simulation cases, whirling flames are found to exist. If a critical gap size, beyond which no whirl can be initiated, exists, it would have to be larger than $24 \mathrm{~cm}$. In this regard, it is instructive to examine the initiation of flame whirl for case 5 at a gap size of $24 \mathrm{~cm}$, as shown by the isotherms and velocity plots shown in Figure 5 for the times instants of $54.0 \mathrm{sec}$ (pre-whirling) and $58.5 \mathrm{sec}$ (post-whirling). It takes a relatively long time to initiate whirl in this case. We have also performed the simulation in this series with a gap size of $45 \mathrm{~cm}$, and the results show that there is no whirl, in agreement with a recent experiment. Consequently, the critical gap size is somewhere between $24 \mathrm{~cm}$ and $45 \mathrm{~cm}$ region. 

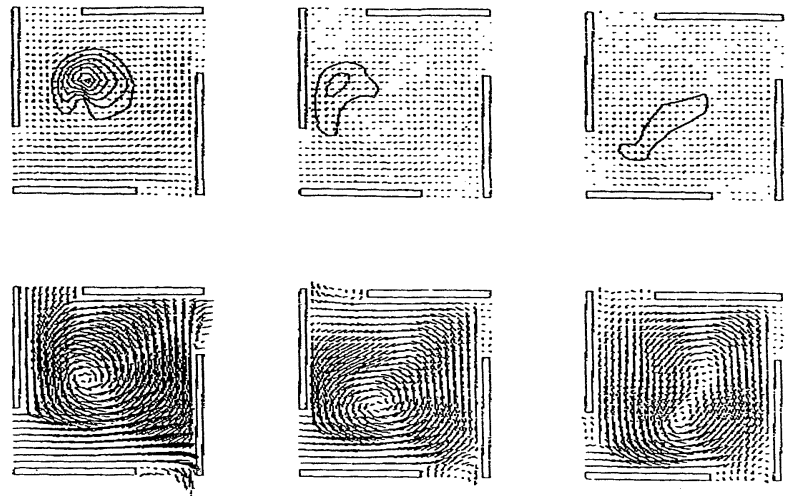

(a)

$54.0 \mathrm{sec}$
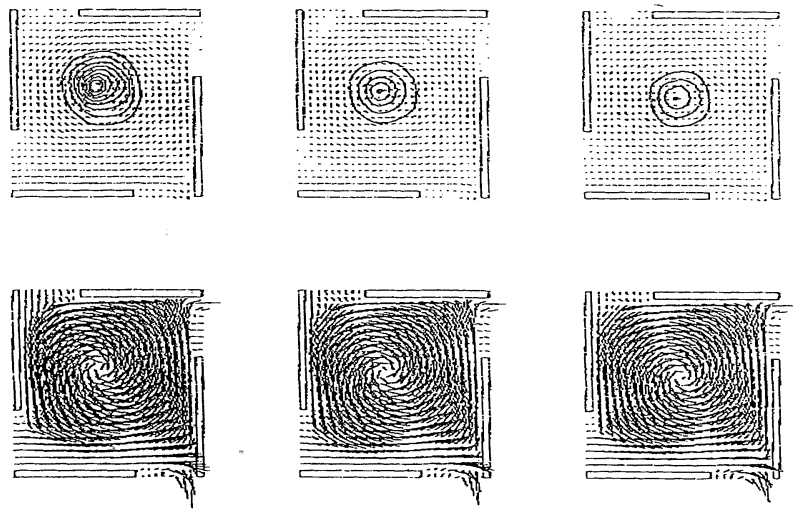

(b)

$58.5 \mathrm{sec}$

FIGURE 5 Temperature ands Velocity Fields at Different Heights of $15 \mathrm{~cm}$, $60 \mathrm{~cm}$, and $120 \mathrm{~cm}$ (Left to Right) from Case 5.

To show the effect of total heat load on the dynamics of the whirling flame, the results of Case 3 with $20 \mathrm{KW}$ can be compared with those of Case 6 at $10 \mathrm{KW}$, since all the other parameters are the same for both cases. While Case 3 shows definitive flame whirls, Case 6 do not appear to lead to flame whirls, or to a very weak whirl at best. That the latter may be the case is from the horizontal-section isotherm plots which show stable centered plumes until $45.0 \mathrm{sec}$ and the plume seems to start to change its regular shape at $49.5 \mathrm{sec}$, suggesting that the whirl, if existing, is breaking down. The maximum mass rate of flow and the maximum flame temperature in Case 6 are $131 \mathrm{~g} / \mathrm{sec}$ and $224 \mathrm{deg}$.C, as compared to $168 \mathrm{~g} / \mathrm{sec}$ and 550 deg. $\mathrm{C}$ for Case 3, respectively. The physical reason behind these differences is perhaps selfevident. 
It was also suggested that the fuel size is expected to have an important effect on the behaviors of the whirling flame [5]. Case 7 for a fuel-area size of $15 \mathrm{~cm} \mathrm{x} 15 \mathrm{~cm}$ and Case 8 for a fuel area size of $21 \mathrm{~cm} \mathrm{x} 21 \mathrm{~cm}$ in Table 1 can be used for comparison to study this effect. It is noted that the enclosure geometry is now given by $180 \mathrm{~cm} \mathrm{x} 63 \mathrm{~cm} \mathrm{x} 63 \mathrm{~cm}$, and that Case 7 has a more concentrated volumetric heat source than that of Case 8. Both fires start to whirl shortly after $32.4 \mathrm{sec}$, and the maximum mass rate of flow at the $1.8 \mathrm{~m}$ height for Case 7 is $225 \mathrm{~g} / \mathrm{sec}$, which is not too different from the corresponding value of $243 \mathrm{~g} / \mathrm{sec}$ for Case 8. However, because of the more concentrated volumetric heat load for Case 7 in a smaller $180 \mathrm{~cm}$ x $63 \mathrm{~cm} \mathrm{x} 63 \mathrm{~cm}$ enclosure, the maximum flame temperature exceeds 1000 deg.C, while that of Case 8 for a larger fuel base is only 588 deg.C. Another interesting difference is that, while both flames whirl, the smaller flame in Case 6 persists in the centered position in the enclosure, and grows in its size as time goes on. In Case 8, however, the whirl starts to rotate in the enclosure in the post-whirling regime. The physical reason is that the entrainment flow would reach the bigger fire in Case 7 sooner, thus causing it to rotate.

Finally, Cases 8,9 , and 10 can be used to give an indication of the effect of enclosure height. In these cases, the flame height is taken to be $90 \mathrm{~cm}$, and consequently for the same $20 \mathrm{KW}$ load, higher flame temperatures can be expected. In Case 8, it is about $588 \mathrm{deg} . \mathrm{C}$, while those of Cases 9 and 10 are somewhat less than 1000 deg.C. The maximum mass rate of flow is only $66.0 \mathrm{~g} / \mathrm{sec}$ for the very short-wall Case 9, and no whirl can be discerned. This is not surprising, since when the flame height is less than the wall height, the flame becomes unstable, thus whirling is more difficult. This was observed in the experiments of Satoh and Yang [5]. On the other hand, the flame in Case 10 reaches the top of the wall and the simulation shows a somewhat weak whirl at $47.2 \mathrm{sec}$ with a maximum mass flow rate of 103 $\mathrm{g} / \mathrm{sec}$. It is noted that in Case 8 where the flame height is well below the wall height (Table 1), whirls do occur and are always very stable, again in good agreement with the observations. The lower maximum flame temperature in this case also signifies the increased ability of the whirling flame to carry upward the heat generated in the lower parts of the flame.

\section{CONCLUDING REMARKS}

In the present numerical study an approximate field model is used to simulate qualitaively the dynamics of whirling flames contained in a square enclosure with symmetrical corner gaps through which entrainment flows, caused by the fire itself, enter into the enclosure. Despite many simplifying assumptions used in the model, it has been shown that the model predicts whirling flame behaviors very similar to what was observed in experiments with real fires. The success of the model is largely due to the fact that the whirling flame is essentially controlled by the entrainment flows which are almost entirely hydrodynamic in nature. The model has been used to predict the following physical effects:

1. The initiation of flame whirls is associated with a sudden increase in the entrainment flows. Stable whirls are generally associated with flame height smaller than the wall height of the square enclosure. The whirling flames tend to reduce the maximum flame temperatures at the lower levels of the flame, provided that the heat load stays the same.

2. The most important physical effect is that of the vertical gap size. An increase in the gap size reduces the entrainment flow, and since strong entrainment flows are necessary to initiate the whirling, a large critical gap size can exist at which no whirling flames can be initiated. The existance of such a critical gap size was observed in the experiments and is consistent with the simulations on the gap-size effect.

3. The flame temperatures are more strongly affected by the magnitude of the volumetric heat source simulating the heat release rate in the fire, and is not particularly sensitive to the gap size. The volumetric heat source is inversely proportional to the size of the fuel pan size and the flame height for a given total heat load. 
4. It is also shown that in those instances where the flame height exceeds the wall height of the enclosure, the entrainment flows through the gaps are reduced accordingly, thus making the initiation of whirls more difficult. For instance, in a simulation case where the wall height is only $2 / 3$ of the flame height, no whirling flame is obtainable.

In view of the results from this simulation study, it is reasonable to state that despite the fact field models at this time are still not capable of predicting real fires, simplified approximate field models, which can capture most of the essential physics in the specific phenomenon, are quite valuable tools, especially when they are used alongside with some good experiments. Whirling fires have also been observed in similar enclosures when one or two of the walls are missing [5]. The same approach can also be used to uncover the essential physics involved. Studies in these additional whirling fire phenomena have been initiated, and results will be reported at a future time.

\section{REFERENCES}

1. Emmons, H. W. and Ying, S. J., "The Fire Whirl," 11th International Combustion Symposium, 475-488, 1966.

2. Soma, S. and Saito, K., "Reconstruction of Fire Whirls Using Scale Models," Combustion \& Flame, 86, 269-284, 1991.

3. Morton, B. R.,"The Physics of Fire Whirls," Fire Research Abstract and Rewiew, 12:1, 1-19, 1970.

4. Satoh, K.,"Study of Whirling Fire Flow in a Cylinder,"1995 Japan Association of Fire Science and Engineering, 86, 1995.

5. Satoh, K. and Yang, K. T., " Experimental Observations of Swirling Fires," 1996 International Mechanical Engineering Congress and Exhibition, Atlanta, ASME HTDVol.335, 393-400, 1996.

6. Saito, K. and Cremers, C. J., "Fire Whirl Enhanced Combustion," Joint ASME/JSME Fluids Engineering Conference, ASME FED-Vol. 220, 1995.

7. Yang, K. T., "Recent Development in Field Modelling of Compartment Fires," JSME International Journal (B), 37:4, 702-717, 1994.

8. Satoh, K., "A Numerical Study of Dynamic Fire Behavior," JSME International Journal (B), 31:3, 402, 1988.

9. Raycraft, J., Kelleher, M. D., Yang, H. Q., and Yang. K. T., "Fire Spread in a ThreeDemensional Pressure Vessel with Radiation Exchange and Wall Heat Losses," Mathematical and Computational Modeling, 14, 795-800, 1990.

10. Satoh, K., "Study of Early and Reliable Fire Detection in Air-Conditioned Rooms," 4th International Fire Safety Symposium, Ottawa, 173, 1994.

11. Yang, K. T., Xia, Q., and Nicolette, V. F., "Simulation of Strong Turbulent Buoyant Flow in a Vented Complex Enclosure," Computational Mechanics, 14:5, 468-479, 1994.

12. Yang, K. T., Nicolette, V. F., and Huang, H. J., "Field Model Simulation of Full Scale Forced-Ventilation Room-Fire Test in the HDR Facility in Germany," Heat Transfer in Fire Combustion Systems, ASME-HTD Vol. 272, 13-20, 1994.

13. Raithby, G. D., "A Critical Evaluation of Upstream Differencing Applied to Problems Involving Fluid Flow," Computer Methods and Application in Mechanical Engineering, 9, 75-103, 1976. 